\title{
An unusual case of co-existing classic mantle cell lymphoma and transformed lymphoma with Burkitt-like features with leukemic presentation
}

\author{
Geling $\mathrm{Li}^{1} \cdot \mathrm{Yi} \mathrm{Zhou}^{1} \cdot$ Sindhu Cherian ${ }^{1} \cdot$ Emily Stevens $^{2}$. \\ Ryan Cassaday $^{2,3} \cdot$ Xueyan Chen $^{1}$
}

Received: 4 February 2016 / Accepted: 26 May 2016 / Published online: 3 June 2016

(C) Springer-Verlag Berlin Heidelberg 2016

\begin{abstract}
Mantle cell lymphoma (MCL) is an aggressive mature B cell lymphoma characterized by the $t(11 ; 14)$ IGH-CCNDI translocation. The majority of the MCL harbors secondary genetic aberrations and the $M Y C$ gene rearrangement is occasionally detected. We reported a unique case of co-existence of a typical MCL and a transformed component with morphologic and immunophenotypic features resembling a Burkitt lymphoma in leukemic phase at disease presentation. Two distinct abnormal B cell populations were identified in the peripheral blood and bone marrow: a CD5+/CD10- population primarily in the peripheral blood (47.6\%) and a CD5 $-/ \mathrm{CD} 10+$ population predominantly in the marrow $(83.8 \%)$, which shared the same surface light chain restriction and identical immunoglobulin gene rearrangements. By cytogenetic studies, the $\mathrm{CD} 10+$ cells harbored both $\mathrm{t}(11 ; 14) I G H-C C N D 1$ and $\mathrm{t}(8 ; 14) I G H-M Y C$ whereas the CD5+ population only carried $\mathrm{t}(11 ; 14) I G H-C C N D 1$. The combined findings indicate that the Burkitt-like component represents a transformation from a typical MCL by acquiring $\mathrm{t}(8 ; 14)$ and that the $M Y C$ rearrangement represents a secondary oncogenic event in MCL that drives the disease progression. This unique case described coexistence of clonally related MCL and a transformed
\end{abstract}

Xueyan Chen

xchen1@uw.edu

1 Department of Laboratory Medicine, University of Washington, 1959 NE Pacific St, Seattle, WA 98195, USA

2 Division of Hematology, University of Washington, Seattle, WA, USA

3 Clinical Research Division, Fred Hutchinson Cancer Research Center, Seattle, WA, USA component otherwise typical of a Burkitt lymphoma, both in leukemic phase at disease presentation, which provided direct evidence on the lymphomagenesis of MCL.

Keywords Mantle cell lymphoma · Burkitt lymphoma MYC $\cdot$ CCND1 - SOX11

\section{Introduction}

Mantle cell lymphoma (MCL) is a mature B cell lymphoma and accounts for approximately $3-10 \%$ of B cell nonHodgkin lymphoma [1]. Classical MCL is characterized by proliferation of atypical small to intermediate sized lymphoid cells that harbor the balanced translocation $\mathrm{t}(11 ; 14)(\mathrm{q} 13 ; \mathrm{q} 32)$. This primary genetic event in MCL juxtaposes the $B C L 1 / C C N D 1$ gene and immunoglobulin heave chain gene $(I G H)$, resulting in constitutional overexpression of cyclin D1 and cell cycle dysregulation at the G1/S phase transition [2]. In addition to the initial oncogenic event, the majority of MCL harbors nonrandom secondary genomic aberrations mainly targeting genes in DNA damage and repair, cell cycle regulation, and cell survival, suggesting genetic progression involving other oncogenic pathways are necessary for MCL lymphomagenesis [2-4]. The typical immunophenotype of MCL is CD5+/CD10-; however, CD10 expression has been reported in 7-8 \% of classical MCL and associated with a germinal center signature without clinical or biological significance $[5,6]$.

MCL is an aggressive lymphoma and has an unfavorable outcome with current therapies, with a median survival of 3-5 years [7]. However, there is increasing evidence that MCL is a heterogeneous disease. The two histologic variants recognized by the 2008 World Health 
Organization (WHO) classification, blastoid and pleomorphic MCL, have a poor prognosis [1]. Blastoid MCL frequently occurs de novo and less commonly may transform from conventional MCL [8]. On the other hand, a subset of MCL patients $(\sim 15 \%)$ presenting with non-nodal disease follows an indolent clinical course with a survival of more than $7-10$ years $[9,10]$. The aggressive behavior has been attributed to the secondary genetic alterations. Of these, MYC gene abnormalities have been described in a subset of MCL, associated with a rapidly progressive clinical course.

We report an unusual case of co-existence of a typical mantle cell lymphoma with $\mathrm{t}(11 ; 14)$ and a clonally related Burkitt-like lymphoma harboring $\mathrm{t}(11 ; 14)$ and $\mathrm{t}(8 ; 14)$, both in leukemic phase at presentation. For the first time, this case clearly demonstrates the transformation of a typical MCL into a Burkitt-like lymphoma by acquiring $t(8 ; 14)$ and provides direct evidence on MCL pathogenesis.

\section{Clinical history}

A 63-year-old gentleman with no significant past medical history presented with mid-back and leg pain and was found to have $\sim 40 \%$ atypical mononuclear cells on the peripheral blood smear. Physical exam revealed no palpable lymphadenopathy or hepatosplenomegaly. A complete blood count showed leukocytosis (white blood cell count of $19.8 \mathrm{~K} / \mu \mathrm{L}$ and absolute lymphocyte count of $13.7 \mathrm{~K} / \mu \mathrm{L}$ ), mild anemia (hemoglobin $10.5 \mathrm{~g} / \mathrm{dL}$ ), and marked thrombocytopenia (platelet count of $19 \mathrm{~K} /$ $\mu \mathrm{L}$ ). Viral serology was negative for CMV and HIV. CT revealed enlarged mesenteric and retroperitoneal lymph nodes and mild splenomegaly, concerning for lymphoma. A bone marrow biopsy was obtained.

\section{Materials and methods}

\section{Histology and immunohistochemistry}

The peripheral blood and bone marrow touch preparation were Wright-Giemsa stained. The bone marrow biopsy was routinely fixed in $10 \%$ neutral buffered formalin, processed, and stained with hematoxylin and eosin. Immunohistochemistry was performed on an automated immunostainer (Leica Bond III) according to established protocols using the following antibodies: CD5 (4C7, Novocastra), CD10 (270, Novocastra), BCL-2 (124, Cell Marque), cyclin D1 (SP4, Thermo Scientific), Ki-67 (MIB1, Dako), BCL-6 (LN22, Leica), and SOX-11 (MRQ-58, Cell Marque). a Peripheral Blood Smear

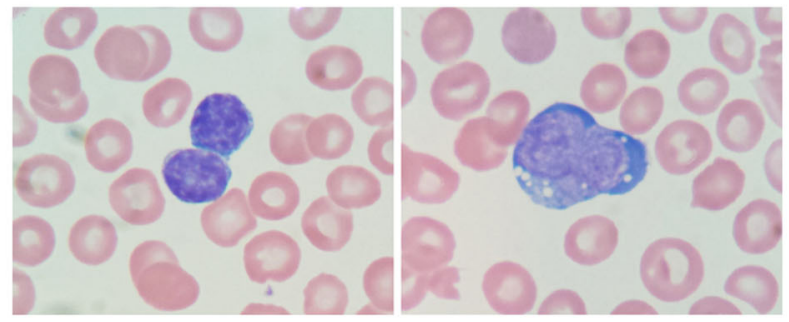

b Peripheral Blood Flow Cytometry
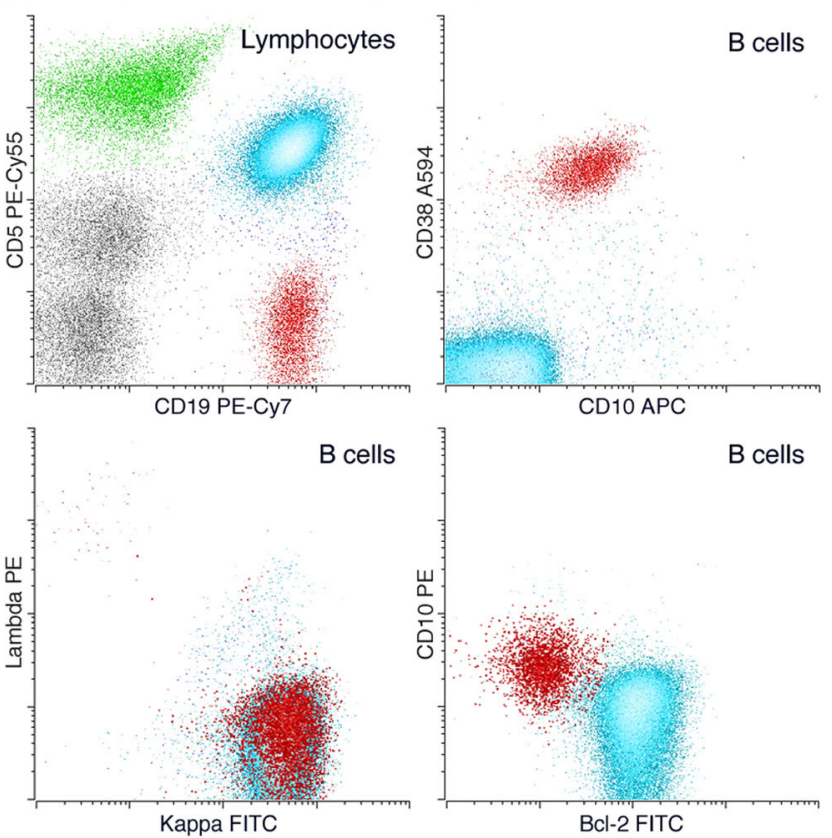

Kappa FITC

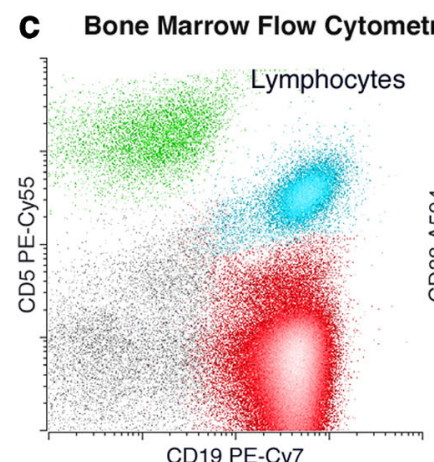

Fig. 1 a Wright-Giemsa-stained peripheral blood smear showing two populations of neoplastic lymphocytes. One population of lymphocytes is small in size with round to oval nuclei, dense chromatin, inconspicuous nucleoli, and scant cytoplasm (left image). The second population of lymphocytes is intermediate to large in size with irregular nuclei, smudged chromatin, moderate amounts of basophilic cytoplasm, and cytoplasmic vacuoles (right image). b Flow cytometric analysis of peripheral blood identified two abnormal B cell populations. The population shown in aqua (47.6\% of the white cells) expresses CD5, CD19, and BCL-2 without CD10 or CD38, and the population shown in $\operatorname{red}(7.3 \%$ of the white cells) expresses CD10, CD19, and CD38 without significant CD5 or BCL-2. Both populations show kappa surface light chain restriction. c Flow cytometric analysis of bone marrow. Two abnormal B cell populations were present with immunophenotype similar to that seen in the peripheral blood. CD5+ population, $7.8 \%$ of the white cells; $\mathrm{CD} 10+$ population, $83.8 \%$ of the white cells 


\section{Flow cytometry}

Flow cytometry analysis was performed on a modified 4-laser, 10-color Becton Dickinson LSRII flow cytometer (BD Biosciences, San Jose, CA) as previously described at UWMC Hematopathology Laboratory [11]. The following laser-fluorochrome combinations were used: (1) 405-nm violet laser (one color) and Pacific blue (PB); (2) 488-nm blue laser (five colors), fluorescein isothiocyanate (FITC), phycoerytherin (PE), PE-Texas red (ECD/PE-TR), PEcyanine (Cy)-5, and PE-Cy7; (3) 594-nm yellow laser (one color) and Alexa Fluor 594 (A594); and (4) 633-nm red laser (three colors), allophycocyanin (APC), APC-Alexa Fluor 700 (A700; BD Biosciences), and APC-Cy7. The specific fluorescently labeled antibodies used in this study were obtained primarily from Beckman Coulter (BC, Fullerton, CA) and Becton Dickinson (BD, San Jose, CA). Antibodies used were as follows: CD20 PB, Kappa FITC, Lambda PE, CD5 PECy5, CD19 PE-Cy7, CD38 A594, CD10 APC, CD45 APCH7, and BCL-2 FITC.

\section{Conventional cytogenetic studies and interphase fluorescence in situ hybridization (IFISH)}

Conventional G-banding karyotype was performed on bone marrow biopsy specimen. IFISH studies used a dual color, dual fusion probe (Vysis) to detect $\mathrm{t}(11 ; 14)$ IGH-CCND1 fusion and a tri-color, dual fusion probe (Vysis) to detect $\mathrm{t}(8 ; 14)$ $I G H-M Y C$ fusion.

\section{Molecular studies}

Immunoglobulin heavy-chain and light-chain gene rearrangements were analyzed by polymerase chain reaction (PCR) using primers designed in-house.

\section{Results}

On review of the peripheral blood smear, two morphologically distinct lymphocyte populations were identified (Fig. 1a). One population was composed of small lymphocytes with round to oval nuclei, condensed chromatin, inconspicuous nucleoli, and scant cytoplasm. In the second population, the lymphocytes were intermediate to large in size with irregular nuclear contours, smudged chromatin, moderate amounts of basophilic cytoplasm, and cytoplasmic vacuoles. Flow cytometry (Fig. 1b) showed two abnormal mature B cell populations: one population (colored aqua; $47.6 \%$ ) had small cell size with expression of CD5, CD19, CD20, BCL-2, FMC-7, and surface kappa light chain restriction without CD10 or CD38; the second population (colored red; $7.3 \%$ ) had increased cell size with expression of CD10, CD19, CD20, CD38, FMC-7, and surface kappa light chain restriction without CD5 or BCL-2. While the immunophenotype of the CD5+ population was most consistent with a MCL, the immunophenotype of the CD10+ population was compatible with an intermediate to largesized B cell lymphoma of germinal center origin, e.g., Burkitt lymphoma (BL), diffuse large B cell lymphoma (DLBCL), or B cell lymphoma, unclassifiable (BCL-U), with features intermediate between BL and DLBCL. The relationship of the two abnormal populations was not entirely clear.

The bone marrow biopsy (Figs. 2a and b) showed a diffuse infiltrate of monotonous, intermediate- to largesized lymphocytes with mildly irregular nuclei, smudged chromatin, variable nucleoli, abundant basophilic cytoplasm, and cytoplasmic vacuoles, similar to that seen in the peripheral blood (Fig. 1a right image). By immunohistochemistry, the neoplastic lymphocytes were positive for CD10 (Fig. 2c), cyclin D1 (Fig. 2d), and BCL-6 and negative for CD5 (Fig. 2e), BCL-2, and SOX-11, with a Ki-67 (Fig. 3f) proliferation index of $>95 \%$. Flow cytometry performed on the marrow biopsy also demonstrated two abnormal mature B cell populations with similar immunophenotype to that identified in the peripheral blood (Fig. 1c), a predominant CD10+ population $(83.8 \%)$ corresponding to the diffuse infiltrate by morphology and a minor CD5+ population (7.8\%) that was not morphologically recognizable. By molecular studies, clonal $I G H$ and $I G K$ gene rearrangements were detected in both flow-sorted CD5+ and CD10+ populations, and the sizes of the PCR products were identical to each other (data not shown), confirming the clonal relationship of the two populations. Cerebrospinal fluid (CSF) was collected on the same day of the marrow procedure and flow cytometry revealed a large population of CD10+ B cells (87.7 \% of the white cells) with an immunophenotype similar to that seen in the marrow and peripheral blood. No abnormal CD5+ B cell population was identified in the CSF.

Chromosomal analysis performed on the bone marrow showed an abnormal karyotype with translocations $\mathrm{t}(11 ; 14)$ and $\mathrm{t}(8 ; 14)$ and an interstitial deletion of $3 \mathrm{q}$ detected in the same cell (Fig. 3). IFISH studies performed on the bone marrow revealed both $\mathrm{t}(8 ; 14) I G H-M Y C$ fusion $(59 \%)$ and $t(11 ; 14) I G N-C C N D 1$ fusion $(62 \%)$ (Fig. 4a). As the neoplastic cells in the marrow were predominantly $\mathrm{CD} 10+(83.8 \%$ of the white cells $)$, the results indicated that the $\mathrm{CD} 10+\mathrm{B}$ cells carried both $\mathrm{t}(11 ; 14)$ and $\mathrm{t}(8 ; 14)$ translocations. However, due to the small size of the CD5+ population $(7.8 \%$ of the white cells), it was unclear whether the CD5+ B cells also harbored the two translocations. To further investigate the 
Fig. 2 Bone marrow biopsy. a Wright-stained touch preparation showing a diffuse infiltrate of monotonous, intermediate to large-sized lymphocytes with mildly irregular nuclei, smudged chromatin, variable nucleoli, moderate amounts of basophilic cytoplasm, and cytoplasmic vacuoles, similar to that seen in the peripheral blood. b H\&Estained bone marrow biopsy showing a diffuse infiltrate of monotonous lymphocytes. By immunohistochemistry, the neoplastic lymphocytes express CD10 (c) and cyclin D1 (d) without CD5 (e). The Ki-67defined proliferation index is $>95 \%$ (f)
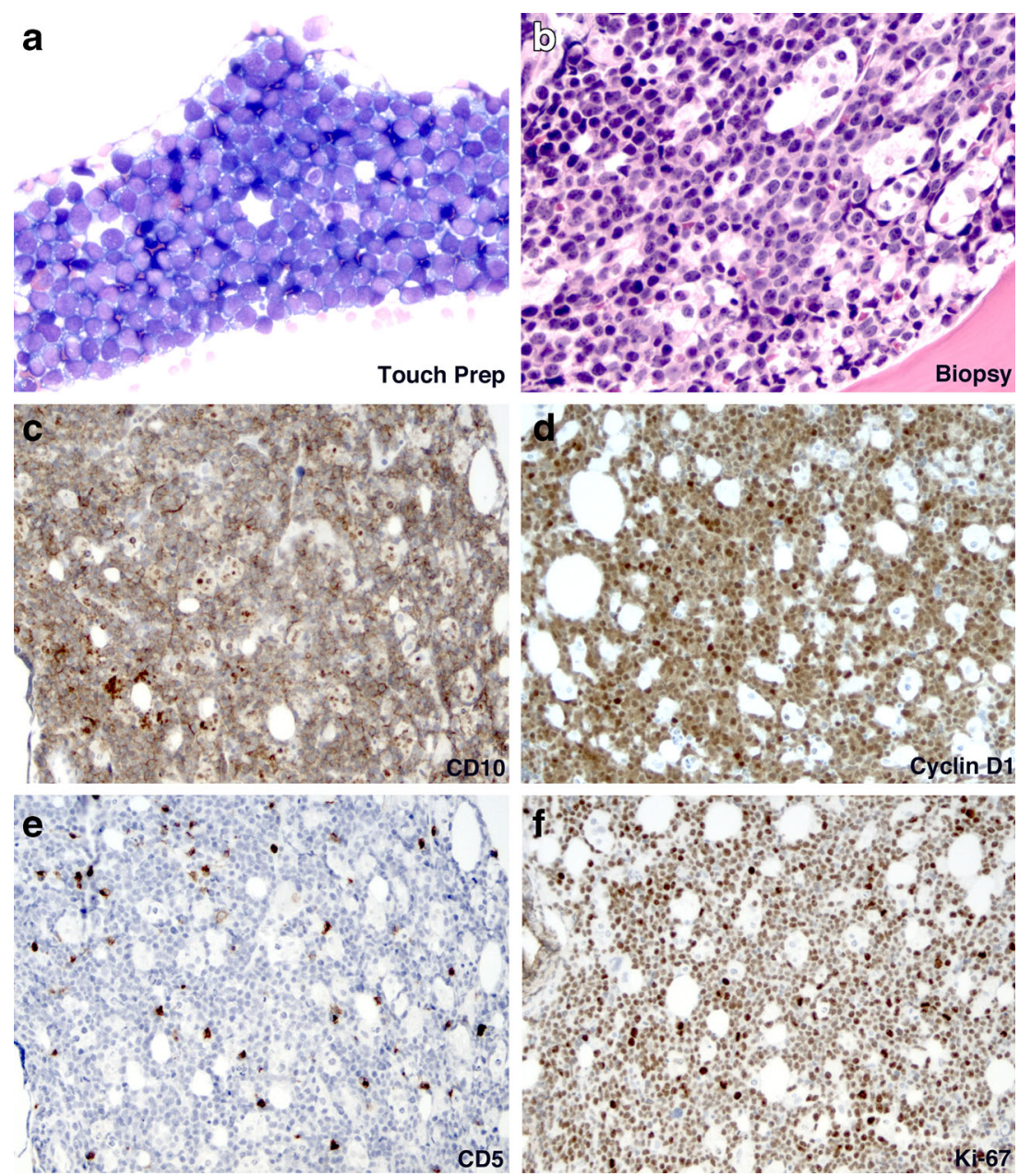

CD5+ population, IFISH studies were performed on the flow-sorted CD5+ B cells from the peripheral blood and showed $\mathrm{t}(11 ; 14) I G H-C C N D 1$ fusion in $99 \%$ of the cells whereas no fusion signals of $\mathrm{t}(8 ; 14) I G H-M Y C$ were detected (Fig. 4b).

Putting all the data together, a pathologic diagnosis of transformed mantle cell lymphoma with Burkitt-like features was made. Systemic chemotherapy initially consisted of R-EPOCH (rituximab with etoposide, prednisone, vincristine, doxorubicin, and cyclophosphamide) for one cycle, but was then transitioned to R-hyper-CVAD (rituximab with cyclophosphamide, vincristine, doxorubicin, and dexamethasone alternating with rituximab, methotrexate, cytarabine, and methylprednisolone) for three additional cycles (i.e., cycles $1 \mathrm{~B}, 2 \mathrm{~A}$, and $2 \mathrm{~B}$ ). The patient also received intrathecal administration of cytarabine and methotrexate. Abnormal B cells were cleared from CSF, peripheral blood, and bone marrow post therapy. Repeat CT post therapy revealed a significant interval decrease in the size of previously enlarged mesenteric and retroperitoneal lymph nodes. The patient then proceeded to receive high-dose chemotherapy with BEAM (bischloroethylnitrosourea (BCNU), etoposide, cytarabine and melphalan) followed by autologous hematopoietic stem cell transplant. Following transplant, he was treated with intrathecal methotrexate monthly for 4 months. $\mathrm{He}$ was in remission 6 months posttransplantation as of December 1, 2015 (13 months after diagnosis).

\section{Discussion}

The $\mathrm{t}(11 ; 14)(\mathrm{q} 13 ; \mathrm{q} 32)$ is the genetic hallmark of MCL and occurs at the pre-B cell stage of differentiation in the bone marrow [12]. This translocation is mediated by recombinase activating gene $1 / 2$ (RAG1/2) and probably low levels of activation-induced cytidine deaminase (AID) [13], resulting in overexpression of cyclin D1 which facilitates G1 progression toward the $\mathrm{S}$ phase. Considering the relatively high frequency of low levels of cells carrying $\mathrm{t}(11 ; 14)$ translocation in healthy individuals $(\sim 8 \% ; 5$ of 71$)$ with persistence of these cells over a long period of time and low occurrence of MCL [14], deregulated overexpression of cyclin D1 is likely 


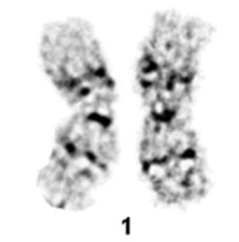

1

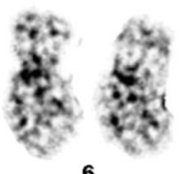

6

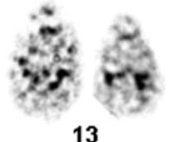

13

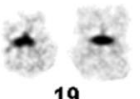

19
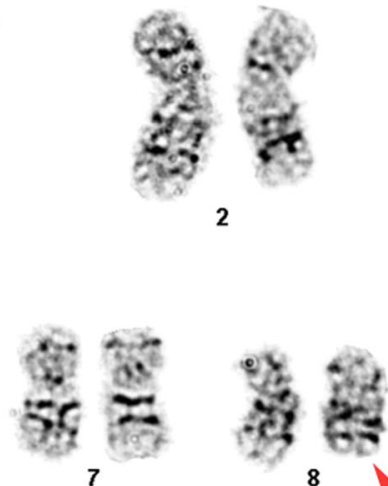

8

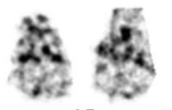

15
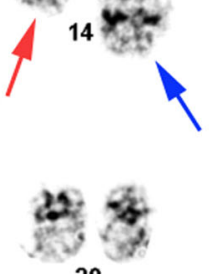

20
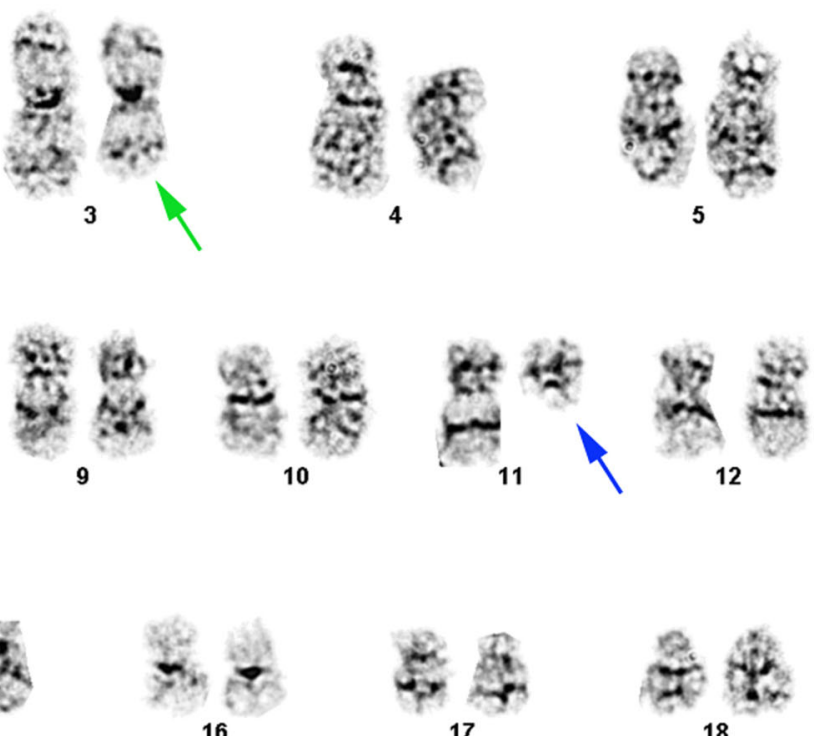

18
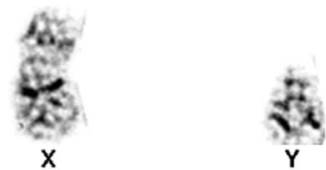
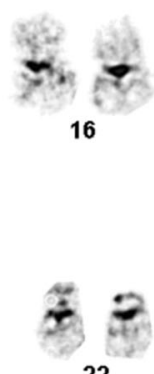

22

Fig. 3 Cytogenetic studies on bone marrow. The karyotype showing both $\mathrm{t}(11 ; 14)$ (blue arrows) and $\mathrm{t}(8 ; 14)$ (red arrows) were present in the same cell. An interstitial deletion of $3 \mathrm{q}$ was also detected (green arrow). ISCN diagnosis: 46,XY,del(3)(q25q26.2),t(8;14)(q24;q32),t(11;14)(q13;q32)[5]/46,XY[15]

insufficient to induce the development of an overt MCL and apparently the synergistic effect from secondary genetic aberrations is required. A high number of $\mathrm{MCL}$ carry non-random secondary genomic aberrations targeting other genes in additional pathways that promote the progression of malignant clones [2-4]. Among those, MYC dysregulation is detected occasionally in MCL and is a significant negative predictor for overall survival [15]. Given that most breakpoints that involve $M Y C$ and $\operatorname{IgH}$ are mediated by AID in mature B cells rather than RAG1/2 in premature B cell precursors [13], MYC rearrangement is a secondary event in $\mathrm{MCL}$, synergistic with cyclin D1 to promote progression along the cell cycle, different from functioning as a primary oncogenic event in BL. Secondary MYC rearrangement, in contrast to $\mathrm{BL}$, often occurs in an unstable genome with complex cytogenetic abnormalities and involves both IG and nonIG loci [16].

Acquisition of $M Y C$ rearrangement in MCL is commonly associated with a blastoid morphology. The immunophenotype is often similar to its predecessor MCL with expression of CD5 and BCL2 without CD10; however, phenotypic heterogeneity has been described. Review of the literature (Table 1) revealed a total of 13 cases with both $\mathrm{t}(11 ; 14)$ and $M Y C$ translocations with IG partners [16-25]. All 13 cases had complex cytogenetic abnormalities in addition to $\mathrm{t}(11 ; 14)$ and $\mathrm{t}(8 ; 14)$ (seven cases), $\mathrm{t}(2 ; 8)$ (four cases), or $\mathrm{t}(8 ; 22)$ (two cases). Twelve cases had peripheral blood involvement; one case had limited CNS involvement. Most of the cases showed a typical MCL immunoprofile or an intermediate immunophenotype with features of both MCL and Burkitt lymphoma. Although patients received chemo- or radiotherapy, the prognosis was poor with median survival of 5 months (range from within 1 to 28 months) after diagnosis. There were additional reported MCL cases carrying $M Y C$ rearrangements with non-IG partners or $M Y C$ amplification [16]. Almost all reported blastoid MCL with both $\mathrm{t}(11 ; 14)$ and $8 \mathrm{q} 24$ abnormalities (including translocation and amplification) carried a complex karyotype with greater than three additional cytogenetic abnormalities and followed an aggressive clinical course. These cases apparently represent a unique subgroup of MCL with unfavorable prognosis.

The case reported herein was distinct from others in that two populations of lymphoma cells with morphologic, immunophenotypic, and cytogenetic features characteristic for typical MCL and BL were identified simultaneously in the peripheral blood and bone marrow at presentation and were derived from the same B cell clone. The BL-like cells 
Fig. 4 IFISH studies on bone marrow (a) and CD5+ B cells sorted from peripheral blood (b). $\mathrm{t}(11 ; 14) I G H-C C N D 1$ fusion was detected in both bone marrow cells (composed predominantly of $\mathrm{CD} 10+\mathrm{B}$ cells) and CD5+ B cells, whereas $\mathrm{t}(8 ; 14) I G H-M Y C$ fusion was only detected in the bone marrow but not the CD5+ B cells. A dual color, dual fusion probe was used to detect $\mathrm{t}(11 ; 14)$ IGH-CCNDI fusion and a tricolor, dual fusion probe was used to detect $\mathrm{t}(8 ; 14) I G H-M Y C$ fusion

\section{a Bone marrow cells}
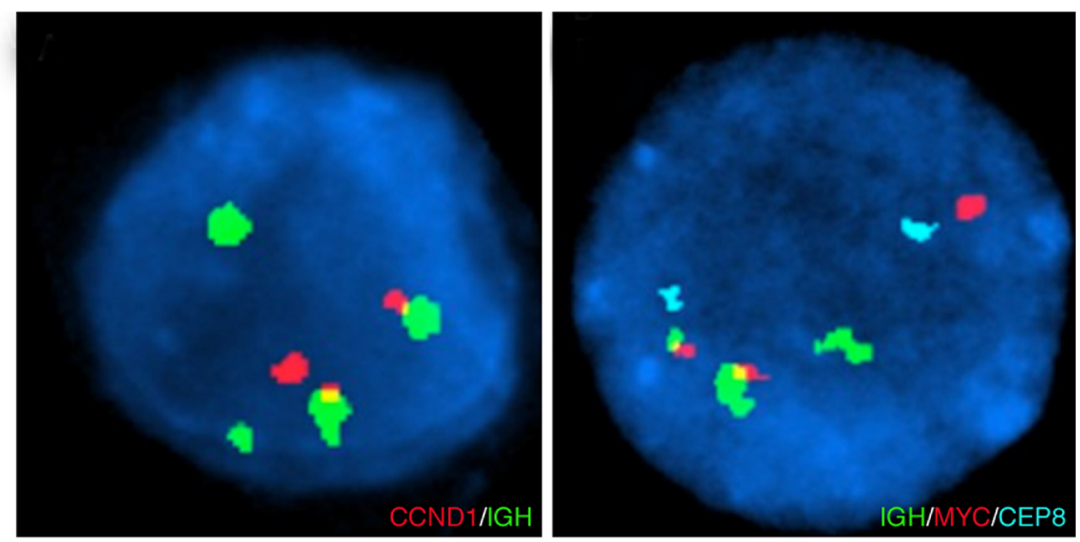

b Peripheral blood CD5+ B cells
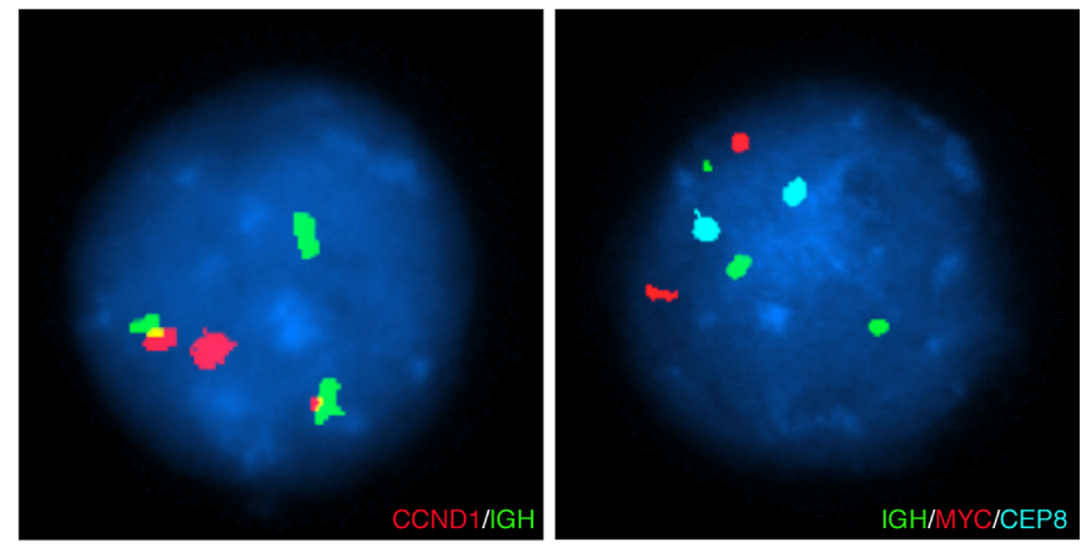

did not retain morphologic or immunophenotypic features of MCL except cyclin D1 expression. Only one additional abnormality besides $\mathrm{t}(8 ; 14)$ and $\mathrm{t}(11 ; 14)$ was identified in BL-like population, in contrast to multiple additional cytogenetic abnormalities indicating genetic instability in other blastoid MCL cases. Given the difference from other blastoid MCL cases, the reported case may dictate a separate pathway of transformation.

SOX11 is a neuronal transcription factor and highly expressed in both cyclin D1-positive and cyclin D1negative MCL [26], suggesting its diagnostic value and perhaps an important factor in lymphomagenesis of MCL. Based on recent data, two different molecular subtypes of MCL have been proposed with difference in gene expression profiles [2,9]. Conventional MCL is genetically unstable, has unmutated or low mutated $I G H V$ genes, expresses high level of SOX11, and may transform into blastoid MCL after genetic progression. Indolent non-nodal MCL has hypermutated IGHV genes, non-complex karyotype, low or no expression of SOX11, and presents predominantly with non-nodal and leukemic disease. Some SOX11-negative MCL may progress rapidly by acquiring genetic mutations in genes such as TP53 [27, 28].
Based on the hypothetical model, the majority of reported blastoid MCLs with MYC rearrangement are derived from SOX11+ mantle zone B cells, accumulate multiple genetic alterations including MYC dysregulation, and progress to blastoid MCL. By contrast, in the reported case, the CD5+ component is likely derived from SOX11- B cells, presents as an indolent non-nodal, leukemic MCL, and progresses to an aggressive component with BL-like morphology and immunophenotype by acquiring $\mathrm{t}(8 ; 14) I G H-M Y C$. A search of literature revealed two other reported cases with presence of both MCL and blastoid populations. Both cases had a reported history of "chronic lymphocytic leukemia" without lymphadenopathy. One case identified two distinct populations, CD5+/CD10- and CD5-/CD10+, and FISH showed $\mathrm{t}(11 ; 14)$ in both populations (MYC status not known) [29]. The second case showed a lymph node with co-existence of a MCL region and a BL-like region with $\mathrm{t}(11 ; 14)$ and $M Y C$ gene rearrangement and expression of weak CD5, CD10, and cyclin D1 without BCL-2 [30]. Although SOX11 stain and karyotype were not available, these two cases may also represent an indolent MCL transformed to an aggressive lymphoma by acquiring additional genetic abnormalities. 


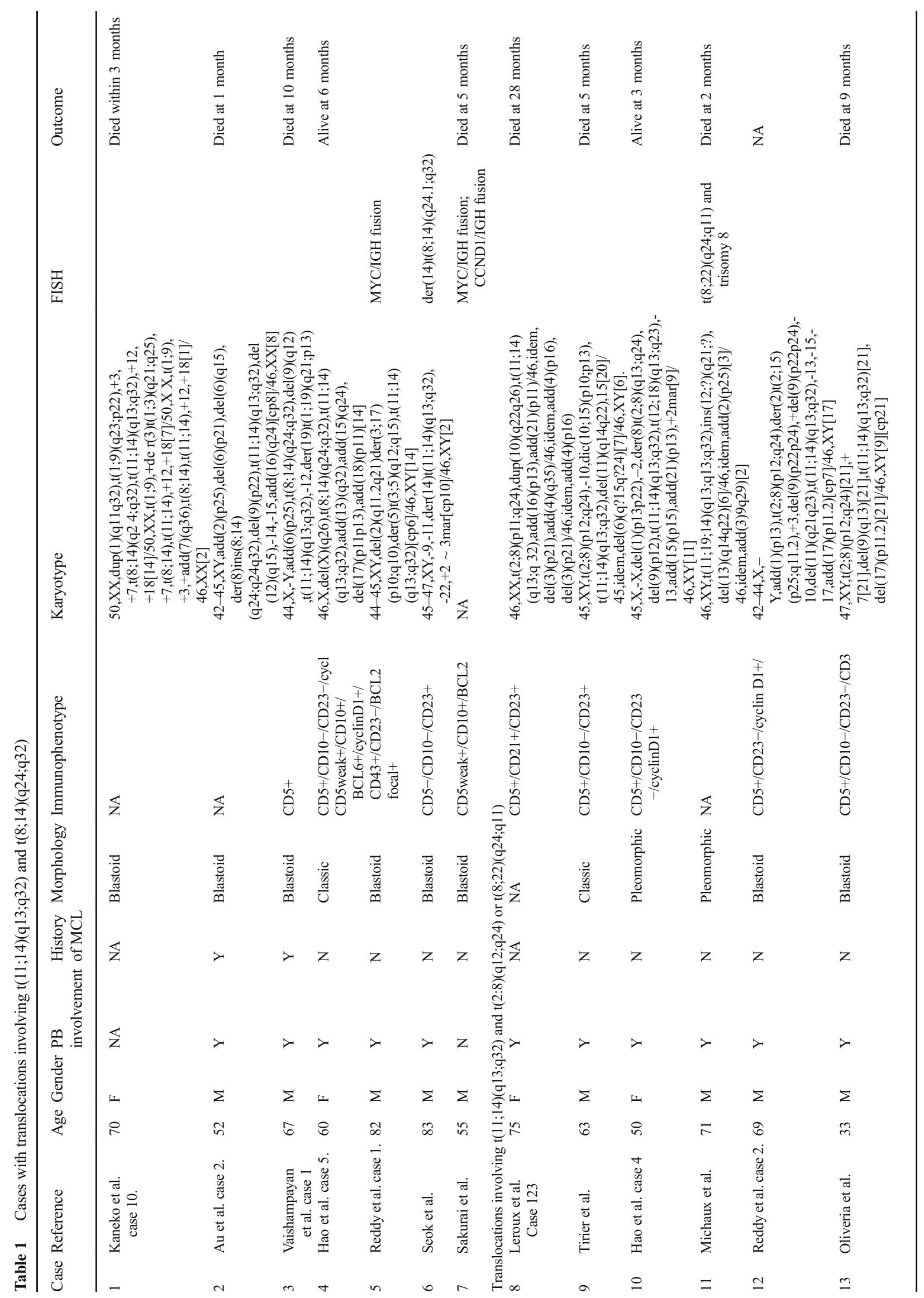


In summary, we described a case of MCL transformed to BL-like lymphoma harboring $\mathrm{t}(11 ; 14)$ and $\mathrm{t}(8 ; 14)$, presenting with two distinct, clonal related populations having typical features of MCL and BL in leukemic phase. For the first time, this case provides direct evidence to support two different pathways in lymphomagenesis of MCL and shed light on the pathogenesis of MCL. Given the aggressive clinical behavior of MCL with $M Y C$ rearrangement, flow cytometry, immunohistochemistry, cytogenetic, and FISH studies are necessary to make the accurate diagnosis for appropriate treatment.

\section{Compliance with ethical standards}

Funding source None.

Conflict of interest The authors declare that they have no conflict of interest.

Ethical approval All procedures performed in studies involving human participants were in accordance with ethical standards of the institutional and/or national research committee and with the 1964 Helsinki declaration and its later amendments or comparable ethical standards.

Informed consent Informed consent was obtained from all individual participants included in the study.

\section{References}

1. Swerdlow SH, Campo E, Harris NL, Jaffe ES, Pileri SA, Stein H, Thiele J, Vardiman JW (2008) WHO classification of tumours of haematopoietic and lymphoid tissues, 4th edn. IARC, Lyon

2. Jares P, Colomer D, Campo E (2007) Genetic and molecular pathogenesis of mantle cell lymphoma: perspectives for new targeted therapeutics. Nat Rev Cancer 7(10):750-762. doi:10.1038/nrc2230

3. Salaverria I, Zettl A, Bea S, Moreno V, Valls J, Hartmann E, Ott G, Wright G, Lopez-Guillermo A, Chan WC, Weisenburger DD, Gascoyne RD, Grogan TM, Delabie J, Jaffe ES, Montserrat E, Muller-Hermelink HK, Staudt LM, Rosenwald A, Campo E (2007) Specific secondary genetic alterations in mantle cell lymphoma provide prognostic information independent of the gene expressionbased proliferation signature. J Clin Oncol Off J Am Soc Clin Oncol 25(10):1216-1222. doi:10.1200/JCO.2006.08.4251

4. Bea S, Valdes-Mas R, Navarro A, Salaverria I, Martin-Garcia D, Jares P, Gine E, Pinyol M, Royo C, Nadeu F, Conde L, Juan M, Clot G, Vizan P, Di Croce L, Puente DA, Lopez-Guerra M, Moros A, Roue G, Aymerich M, Villamor N, Colomo L, Martinez A, Valera A, Martin-Subero JI, Amador V, Hernandez L, Rozman M, Enjuanes A, Forcada P, Muntanola A, Hartmann EM, Calasanz MJ, Rosenwald A, Ott G, Hernandez-Rivas JM, Klapper W, Siebert R, Wiestner A, Wilson WH, Colomer D, Lopez-Guillermo A, Lopez-Otin C, Puente XS, Campo E (2013) Landscape of somatic mutations and clonal evolution in mantle cell lymphoma. Proc Natl Acad Sci U S A 110(45):18250-18255. doi:10.1073/pnas. 1314608110
5. Akhter A, Mahe E, Street L, Pournazari P, Perizzolo M, ShabaniRad MT, Stewart DA, Mansoor A (2015) CD10-positive mantle cell lymphoma: biologically distinct entity or an aberrant immunophenotype? Insight, through gene expression profile in a unique case series. J Clin Pathol 68(10):844-848. doi:10.1136/ jclinpath-2015-202955

6. Gao J, Peterson L, Nelson B, Goolsby C, Chen YH (2009) Immunophenotypic variations in mantle cell lymphoma. Am J Clin Pathol 132(5):699-706. doi:10.1309/AJCPV8LN5ENMZOVY

7. Vose JM (2012) Mantle cell lymphoma: 2012 update on diagnosis, risk-stratification, and clinical management. Am J Hematol 87(6): 604-609. doi:10.1002/ajh.23176

8. Shrestha R, Bhatt VR, Guru Murthy GS, Armitage JO (2015) Clinicopathologic features and management of blastoid variant of mantle cell lymphoma. Leuk Lymphoma:1-9. doi:10.3109/ 10428194.2015.1026902

9. Hsi ED, Martin P (2014) Indolent mantle cell lymphoma. Leuk Lymphoma 55(4):761-767. doi:10.3109/10428194.2013.815353

10. Martin P, Chadburn A, Christos P, Weil K, Furman RR, Ruan J, Elstrom R, Niesvizky R, Ely S, Diliberto M, Melnick A, Knowles DM, Chen-Kiang S, Coleman M, Leonard JP (2009) Outcome of deferred initial therapy in mantle-cell lymphoma. J Clin Oncol Off J Am Soc Clin Oncol 27(8):1209-1213. doi:10. 1200/JCO.2008.19.6121

11. Wood B (2006) 9-Color and 10-color flow cytometry in the clinical laboratory. Arch Pathol Lab Med 130(5):680-690. doi:10.1043/ 1543-2165(2006)130[680:CACFCI]2.0.CO;2

12. Welzel N, Le T, Marculescu R, Mitterbauer G, Chott A, Pott C, Kneba M, Du MQ, Kusec R, Drach J, Raderer M, Mannhalter C, Lechner K, Nadel B, Jaeger U (2001) Templated nucleotide addition and immunoglobulin JH-gene utilization in $\mathrm{t}(11 ; 14)$ junctions: implications for the mechanism of translocation and the origin of mantle cell lymphoma. Cancer Res 61(4):1629-1636

13. Aukema SM, Siebert R, Schuuring E, van Imhoff GW, KluinNelemans HC, Boerma EJ, Kluin PM (2011) Double-hit B-cell lymphomas. Blood 117(8):2319-2331. doi:10.1182/blood-201009-297879

14. Lecluse Y, Lebailly P, Roulland S, Gac AC, Nadel B, Gauduchon P (2009) t(11;14)-Positive clones can persist over a long period of time in the peripheral blood of healthy individuals. Leukemia 23(6):1190-1193. doi:10.1038/leu.2009.31

15. Hartmann E, Fernandez V, Moreno V, Valls J, Hernandez L, Bosch F, Abrisqueta P, Klapper W, Dreyling M, Hoster E, Muller-Hermelink HK, Ott G, Rosenwald A, Campo E (2008) Five-gene model to predict survival in mantle-cell lymphoma using frozen or formalin-fixed, paraffin-embedded tissue. J Clin Oncol Off J Am Soc Clin Oncol 26(30):4966-4972. doi:10. 1200/JCO.2007.12.0410

16. Hao S, Sanger W, Onciu M, Lai R, Schlette EJ, Medeiros LJ (2002) Mantle cell lymphoma with 8q24 chromosomal abnormalities: a report of 5 cases with blastoid features. Mod Pathol 15(12):12661272. doi:10.1097/01.MP.0000037310.82136.99

17. Au WY, Horsman DE, Viswanatha DS, Connors JM, Klasa RJ, Gascoyne RD (2000) 8q24 Translocations in blastic transformation of mantle cell lymphoma. Haematologica 85(11):1225-1227

18. Kaneko Y, Rowley JD, Variakojis D, Haren JM, Ueshima Y, Daly K, Kluskens LF (1983) Prognostic implications of karyotype and morphology in patients with non-Hodgkin's lymphoma. Int J Cancer 32(6):683-692

19. Leroux D, Le Marc'Hadour F, Gressin R, Jacob MC, Keddari E, Monteil M, Caillot P, Jalbert P, Sotto JJ (1991) Non-Hodgkin's lymphomas with $\mathrm{t}(11 ; 14)(\mathrm{q} 13 ; \mathrm{q} 32)$ : a subset of mantle zone/intermediate lymphocytic lymphoma? Br J Haematol 77(3):346-353

20. Michaux L, Wlodarska I, Theate I, Stul M, Scheiff JM, Deneys V, Ferrant A, Hagemeijer A (2004) Coexistence of BCL1/CCND1 and 
CMYC aberrations in blastoid mantle cell lymphoma: a rare finding associated with very poor outcome. Ann Hematol 83(9):578-583. doi:10.1007/s00277-004-0879-2

21. Reddy K, Ansari-Lari M, Dipasquale B (2008) Blastic mantle cell lymphoma with a Burkitt translocation. Leuk Lymphoma 49(4): 740-750. doi:10.1080/10428190701852024

22. Sakurai H, Sugimoto KJ, Shimada A, Imai H, Wakabayashi M, Sekiguchi Y, Ota Y, Izutsu K, Takeuchi K, Komatsu N, Noguchi M (2015) Primary CNS CCND1/MYC-positive double-hit Bcell lymphoma: a case report and review of the literature. J Clin Oncol Off J Am Soc Clin Oncol 33(19):e79-e83. doi:10.1200/ JCO.2013.49.1316

23. Seok Y, Kim J, Choi JR, Kim YR, Park SJ, Kim SJ, Song J, Lee KA (2012) CD5-negative blastoid variant mantle cell lymphoma with complex CCND1/IGH and MYC aberrations. Ann Lab Med 32(1): 95-98. doi:10.3343/alm.2012.32.1.95

24. Tirier C, Zhang Y, Plendl H, Weber-Matthiesen K, Langer W, Heit W, Schlegelberger B (1996) Simultaneous presence of $t(11 ; 14)$ and a variant Burkitt's translocation in the terminal phase of a mantle cell lymphoma. Leukemia 10(2):346-350

25. Vaishampayan UN, Mohamed AN, Dugan MC, Bloom RE, Palutke M (2001) Blastic mantle cell lymphoma associated with Burkitt-type translocation and hypodiploidy. Br J Haematol 115(1):66-68
26. Ek S, Dictor M, Jerkeman M, Jirstrom K, Borrebaeck CA (2008) Nuclear expression of the non B-cell lineage Sox11 transcription factor identifies mantle cell lymphoma. Blood 111(2):800-805. doi: 10.1182/blood-2007-06-093401

27. Royo C, Navarro A, Clot G, Salaverria I, Gine E, Jares P, Colomer D, Wiestner A, Wilson WH, Vegliante MC, Fernandez V, Hartmann EM, Trim N, Erber WN, Swerdlow SH, Klapper W, Dyer MJ, Vargas-Pabon M, Ott G, Rosenwald A, Siebert R, Lopez-Guillermo A, Campo E, Bea S (2012) Non-nodal type of mantle cell lymphoma is a specific biological and clinical subgroup of the disease. Leukemia 26(8):1895-1898. doi:10.1038/leu.2012.72

28. Nygren L, Baumgartner Wennerholm S, Klimkowska M, Christensson B, Kimby E, Sander B (2012) Prognostic role of SOX11 in a population-based cohort of mantle cell lymphoma. Blood 119(18):4215-4223. doi:10.1182/blood-2011-12-400580

29. Morice WG, Hodnefield JM, Kurtin PJ, Hanson CA (2004) An unusual case of leukemic mantle cell lymphoma with a blastoid component showing loss of CD5 and aberrant expression of CD10. Am J Clin Pathol 122(1):122-127. doi:10.1309/UD2C6JVP-WHXQ-Q217

30. Felten CL, Stephenson CF, Ortiz RO, Hertzberg L (2004) Burkitt transformation of mantle cell lymphoma. Leuk Lymphoma 45(10): 2143-2147. doi:10.1080/10428190410001711479 